\title{
7 \\ Protocol for Handling and Disposal of the Dead Bodies in Covid-19
}

\section{IJCRR}

Section: Healthcare Sci. Journal Impact Factor: 6.1 (2018) ICV: 90.90 (2018)

(c) (i) (8)

Copyright@IJCRR

\section{Sampada V. Late1 ${ }^{1}$, Harsha Keche ${ }^{2}$, V. K. Chimurkar³ ${ }^{3}$ Vaibhav Anjankar ${ }^{4}$}

'PG Student, Department of Anatomy, Jawaharlal Nehru Medical College, Sawangi(M), Datta Meghe Institute of Medical Science (Deemed to be University), Sawangi (M), Wardha, India; 'P Professor, Department of Anatomy, Jawaharlal Nehru Medical College, Sawangi(M), Datta Meghe Institute of Medical Science (Deemed to be University), Sawangi (M), Wardha, India; 3Professor and Head, Department of Anatomy, Jawaharlal Nehru Medical College, Sawangi(M), Datta Meghe Institute of Medical Science (Deemed to be University), Sawangi (M), Wardha, India; ${ }^{4}$ Associate Professor, Department of Anatomy, Jawaharlal Nehru Medical College, Sawangi(M), Datta Meghe lnstitute of Medical Science (Deemed to be University), Sawangi (M), Wardha, India.

\section{ABSTRACT}

COVID 19 is an acute respiratory illness caused by COVID 19 virus that directly affects the lungs. Based on current pieces of evidence and researches, the COVID 19 virus is transmitted between peoples and communities through droplets, fomites and close contact with an infected person, with possible spread with faeces. It is not an airborne disease. As this is a new virus whose sources and disease progression are not yet totally clear. Except in cases of hemorrhagic fever such as Ebola, Marburg and cholera, dead bodies are not infectious. Only those patients having lung disease-causing pandemic influenza, if handled improperly during an autopsy, can be infectious. Otherwise, cadavers do not transmit diseases. It is a generally common myth that a person who has died from the communicable disease should be cremated, but this is not true. To date there is no evidence of a person has become infected from exposure and contact with bodies of persons who died from COVID 19. The safety and wellbeing of everyone who tends to handle the bodies should be the priority. WHO, Ministry of Health, Family welfare has given some important guidelines on handling dead bodies in hospital setups, with the standard of precautions. They also have given guidelines on the transportation of bodies, autopsy, environmental cleaning. Before contact with bodies, health care worker should ensure that necessary hand hygiene and personal protective equipment are being used. Hasty disposal of a dead from COVID 19 should be avoided.

Key Words: Airborne disease, Cadaver, COVID 19, Droplets, Ministry of Health and family welfare, PPE, WHO

\section{INTRODUCTION}

All dead bodies are potentially infectious and standard precautions should be applied to every case. Although most organisms in the body are unlikely to infect a healthy person. Some infectious organism agents may be transmitted when a person is in contact with blood, body fluid or tissue of the dead body of a person with infectious disease. To minimize the risk of transmission of unknown and unspecified infectious diseases, dead bodies should be handled in such a way that worker's exposure to blood and fluid of dead bodies, body fluid, or tissue is reduced. ${ }^{1}$ A rational approach should include staff training and education about how to handle dead bodies of the infectious patient, ${ }^{2}$ a safe working environment for workers and the availability of personal protective equipment in hospitals. ${ }^{3}$
WHO, Ministry of Health, Family Welfare guidelines given in pandemic situation on handling COVID 19 patients dead bodies, transportation, autopsy, environmental cleaning, preparing and packing of dead bodies, mortuary care, etc. with standards of precaution procedure and use of PPE properly. 3,4 In this pandemic situation, health workers have programs to enhance their practices in the pandemic situation and its implementation on the patient to fast recover and stop spreading infections. ${ }^{5}$

\section{Preparing and packing the body}

According to WHO guidelines on infection prevention and control of the dead body in COVID19. Preparing and packing of a dead body with a standard of precautions. ${ }^{4}$

\section{Corresponding Author:}

Dr. Harsha Keche, Professor, Department of Anatomy, Jawaharlal Nehru Medical College, Sawangi(M), Datta Meghe Institute of Medical Sciences, Wardha, Maharashtra, India; Email: drharshakeche@rediffmail.com

ISSN: 2231-2196 (Print)

Received: 28.08 .2020
ISSN: 0975-5241 (Online)

Revised: 21.10 .2020
Accepted: 24.11 .2020
Published: 05.01 .2021 
- Ensure that the health workers, mortuary staff, or the burial team, interacting with the dead body, should apply standard precautions for the safeguard. ${ }^{4,6}$

- Hand hygiene should be followed before and after interacting with the dead body and surrounding environment. $^{7}$

- Appropriate personal protective equipment including gown and gloves should be used according to the level of contact with the dead body.

- If there is risk of splashes of body fluids or secretions, the facial shields or goggles and medical masks should be used by health care or mortuary staff.

- When transferring the body to the mortuary, all intravenous lines, catheter and other medical equipment or tubes should be removed.

- Ensure nobody fluids are leaking from orifices.

- To minimize the movement and handling of the body.

- Wrap the body properly in cloth and transfer the body as soon as possible to the mortuary area.

- There is no need to disinfect the body before transferring to the mortuary area.

\section{Mortuary care}

Ministry of health and family welfare has given guidelines for dead body management and Mortuary care. ${ }^{4}$

- Health care staff or mortuary staff should prepare the body e.g. washing body, tidying hair, trimming nails, or shaving.

- Health care staff or mortuary staff should wear appropriate PPE according to standard precaution like gloves, impermeable disposable gown, medical mask, eye protection, shield.

- If the family wished to view the body of the patient and not to touch, they may do this, using standard precautions at all times including hand hygiene. Instruct the family don't touch or kiss the body.

- Embalming is not recommended to avoid excessive manipulation of the body.

- Elderly people above age 60 and an immunosuppressed person should not directly interact with the body. ${ }^{2,7}$

\section{Handling of a dead body in Mortuary}

WHO and Ministry of Health gave some guidelines on how to handles dead bodies in a mortuary with a standard of precautions. ${ }^{6,8}$

- Mortuary staff or mortuary workers handling COVID 19 dead bodies should handle and observe standard precautions. ${ }^{9}$

- Dead bodies should be stored in the Mortuary cold chamber and maintained the temperature at $4{ }^{\circ} \mathrm{C}$.

- After removing the body from mortuary, the chamber door, handles, the floor should be clean immediately with sodium hypochlorite $1 \%$ solution. ${ }^{5,9}$

\section{Transportation}

WHO and $\mathrm{MOH}$ guidelines on transportation. WHO guidelines mention that no specific equipment or vehicles required for transportation of COVID 19 patient's dead bodies. ${ }^{10}$

- The body securely packed in a body bag and the exterior of which is decontaminated poses no additional risk to the staff transporting the dead bodies.

- Those workers handling dead bodies during transportation may follow standard precaution equipment.

- After transportation of the body to cremation or burial, staff will be decontaminated with $1 \%$ sodium hypochlorite.

\section{Autopsy and Environmental control}

WHO and Family Welfare have given clear guidelines on autopsy and environmental control. That can prevent medical staff and hospital workers from infections. ${ }^{10}$

- For a diseased person with COVID-19, the protection protocol should be compatible with that used with other autopsies of people who have died of an acute respiratory disease. ${ }^{11}$

- The lungs and other organs can still contain live viruses if a person dies during the infectious period of COVID-19. ${ }^{11}$

- Additional respiratory protection is needed during the procedure that generates small particle aerosols, such as the use of power saws.

- If a body with suspected or confirmed with COVID 19 is selected for autopsy, health care facilities must ensure that safety precaution is placed to protect those performing the autopsy. ${ }^{8}$

- Performing autopsy procedure inadequately ventilated room.

- Should involve minimum staff in autopsy procedure.

- Appropriated PPE should be used when performing the autopsy procedures. ${ }^{12}$

\section{Environmental cleaning and control}

WHO has given specific guidelines on environmental cleaning and control in COVID 19 pandemic situation. Coronavirus can remain live on a surface for up to 9 days. ${ }^{13}$ COVID 19 viruses have been detected after up to 72 hours in experimental conditions. ${ }^{14}$ therefore, cleaning the environment is paramount. ${ }^{4}$

- The mortuary must be kept clean and properly ventilated environment at all times.

- Lighting in the room must be adequate.

- Instruments and surface area must be disinfected and maintained between autopsies.

- The instruments which will be used in autopsies that should be clean immediately after the procedure.

- Environment surface and the surface area should be first cleaned with soap and water or commercially prepared detergent solution where bodies were prepared.

- When preparing disinfecting solution personnel 
should use appropriate PPE, including respiratory and eye protection. ${ }^{14}$

\section{Burial}

According to WHO guidelines implementation. People who have died from COVID 19 can be buried or cremated. ${ }^{4}$

- Following customs family and friends may view the body after it has been prepared for burial.

- Do not touch or kiss the body and should wash hands thoroughly with soap or sanitizer after viewing the body. ${ }^{15}$

- Those who are placing the body in the grave, on the funeral pyre, etc., should wear gloves, mask and wash hands after removal of gloves after burial is complete.

\section{CONCLUSION}

COVID 19 is an acute respiratory illness caused by COVID 19 virus that directly affects the lungs. As this is a new virus whose sources and disease progression are not yet totally clear. Although most organisms in the body are unlikely to infect a healthy person. Some infectious organism agents may be transmitted when a person is in contact with blood, body fluid or tissue of the dead body of a person with infectious disease. To minimize the risk of transmission of unknown and unspecified infectious diseases, dead bodies should be handled in such a way that worker's exposure to blood and fluid of dead bodies, body fluid, or tissue is reduced. WHO, Ministry of Health, Family Welfare guidelines given in pandemic situation on handling COVID 19 patients dead bodies, transportation, autopsy, environmental cleaning, preparing and packing of dead bodies, mortuary care, etc. with standards of precaution procedure and use of PPE properly.

\section{ACKNOWLEDGMENT}

Authors acknowledge the immense help received from the scholars whose articles are cited and included in references to this manuscript. The authors are also grateful to authors / editors / publishers of all those articles, journals, and books from which the literature for this article has been reviewed and discussed.

\section{Funding/Support: None}

Conflict of interest: There are no conflicts of interest in this work.

\section{REFERENCES}

1. Chavez S, Long B, Koyfman A, Liang SY. Coronavirus Disease (COVID-19): A primer for emergency physicians. Am J Emerg Med 2020;S0735-6757(20):30178-9.

2. Meng L, Hua F, Bian Z. Coronavirus disease 2019 (COVID-19): emerging and future challenges for dental and oral medicine. J Dental Res 2020;99(5):481-7.

3. Morgan O, Tidball-Binz M, Van Alphen D. Management of dead bodies after disasters: a field manual for first responders. Pan American Health Organization (PAHO); 2006.

4. Curran ET. Standard precautions: what is meant and what is not. J Hosp Info 2015 May;90(1):10.

5. World Health Organization. Infection prevention and control during health care when novel coronavirus $(\mathrm{nCoV})$ infection is suspected: interim guidance, 25 January 2020.

6. World Health Organization. Infection prevention and control during health care when COVID-19 is suspected: interim guidance, 19 March 2020. World Health Organization; 2020.

7. Verbyla ME, Pitol AK, Navab-Daneshmand T, Marks SJ, Julian TR. Safely Managed Hygiene: A Risk-Based Assessment of Handwashing Water Quality. Environmental Sci Tech 2019;53(5):2852-61.

8. Hanley B, Lucas SB, Youd E, Swift B, Osborn M. Autopsy in suspected COVID-19 cases. J Clin Path 2020;73(5):239-42.

9. Lamontagne F, Angus DC. Toward universal deployable guidelines for the care of patients with COVID-19. JAMA 2020;323(18):1786-7.

10. Chartier Y, Pessoa-Silva CL. Natural ventilation for infection control in health-care settings. World Health Organization; 2009.

11. Ghinai I, McPherson TD, Hunter JC, Kirking HL, Christiansen D, Joshi K, et al. First known person-to-person transmission of severe acute respiratory syndrome coronavirus 2 (SARS-CoV-2) in the USA. Lancet 2020;395: 1137-44.

12. Interim US. Guidance for Risk Assessment and Public Health Management of Healthcare Personnel with Potential Exposure in a Healthcare Setting to Patients with Coronavirus Disease 2019 (COVID-19): Centers for Disease Control and Prevention; 2020. Center for Disease Control and Prevention. 2020.

13. Kampf G, Todt D, Pfaender S, Steinmann E. Persistence of coronaviruses on inanimate surfaces and their inactivation with biocidal agents. J Hosp Info 2020;104(3):246-51.

14. Van Doremalen N, Bushmaker T, Morris DH, Holbrook MG, Gamble A, Williamson BN, Tamin A, Harcourt JL, Thornburg NJ, Gerber SI, Lloyd-Smith JO. Aerosol and surface stability of SARS-CoV-2 as compared with SARS-CoV-1. New Engl J Med 2020;382(16):1564-7.

15. World Health Organization. Water, sanitation, hygiene, and waste management for the COVID-19 virus: interim guidance, 23 April 2020. World Health Organization; 2020. 